\title{
A. Simon, Trafics de Proust. Merleau-Ponty, Sartre, Deleuze, Barthes
}

\section{Davide Vago}

\section{Q OpenEdition}

1 Journals

\section{Edizione digitale}

URL: http://journals.openedition.org/studifrancesi/10044

DOI: 10.4000/studifrancesi. 10044

ISSN: 2421-5856

\section{Editore}

Rosenberg \& Sellier

\section{Edizione cartacea}

Data di pubblicazione: 1 août 2017

Paginazione: 394-395

ISSN: 0039-2944

\section{Notizia bibliografica digitale}

Davide Vago, «A. Simon, Trafics de Proust. Merleau-Ponty, Sartre, Deleuze, Barthes», Studi Francesi

[Online], 182 (LXI | II) | 2017, online dal 18 octobre 2017, consultato il 09 janvier 2021. URL: http:// journals.openedition.org/studifrancesi/10044; DOI: https://doi.org/10.4000/studifrancesi.10044

Questo documento è stato generato automaticamente il 9 janvier 2021.

\section{(c) (i) (9)}

Studi Francesi è distribuita con Licenza Creative Commons Attribuzione - Non commerciale - Non opere derivate 4.0 Internazionale. 


\title{
A. Simon, Trafics de Proust. Merleau- Ponty, Sartre, Deleuze, Barthes
}

\author{
Davide Vago
}

\section{NOTIZIA}

ANNE SIMON, Trafics de Proust. Merleau-Ponty, Sartre, Deleuze, Barthes, Paris, Hermann, 2016, «Philosophie», $242 \mathrm{pp}$.

1 Con questo saggio Anne Simon torna a un momento cruciale della filosofia francese, negli anni Sessanta del secolo scorso, al fine di mostrare come il confronto con il romanzo di Marcel Proust abbia strutturato il pensiero di Merleau-Ponty, Sartre, Deleuze e Barthes. Nella prima parte («Plasticité de Proust», pp. 7-38), l'A. insiste su come la lettura di Proust sia in grado di trasformare i meccanismi del pensiero degli autori presi in considerazione: un certo modo di interpretare, financo di deformare Proust, riconfigura infatti le nozioni di soggetto, di corpo e di realtà sensibile, polarizzando la pratica del pensiero in precise direzioni. In questo processo, la Recherche viene addirittura distorta, ed è proprio l'idea di commercio clandestino («trafic») che interessa a Simon. Negli anni in cui si assiste alla "resurrezione" di Proust nella sua stessa patria, tali pensatori si accostano a un autore che sembra, tra l'altro, proporre riflessioni filosofiche attraverso un'inedita modalità narrativa e stilistica.

2 Che il pensiero di Merleau-Ponty si sia nutrito costantemente di Proust è un dato acquisito; in «L'alter-ego (Merleau-Ponty)» (pp. 39-79), Simon insiste piuttosto su come esista uno «style de pensée» comune ai due autori: la porosità della frontiera tra oggetto e soggetto; il sodalizio tra incarnazione ed espressione; la «syntaxe» del mondo sensibile e via dicendo, altrettante somiglianze che portano l'A. a mostrare come la riflessione del filosofo si sia costantemente intrecciata con Proust. Attraverso il suo alter ego, il pensiero di Merleau-Ponty arriva a scorciatoie inesplorate: l'«obliquità» della sua prosa è un chiaro debito nei confronti dello scrittore. A ciò si aggiunge la 
tematica dell'alterità, il ruolo dell'impressione e del corpo, la "trama" del reale in cui ciò che è occultato conta quanto ciò che appare.

Il rapporto di Sartre con Proust è apparentemente opposto. Ne «Le frère ennemi (Sartre)» (pp. 81-115) l'A. mostra che se Proust sembra incarnare agli occhi di Sartre il cancro della letteratura d'introspezione, la relazione tra i due è molto più sfaccettata: fin da giovane il teorico dell'esistenzialismo ha intuito il potere ontologico della metafora proustiana. È soprattutto una concezione conflittuale dello sguardo verso l'altro che accomuna i due: una crudele focalizzazione esterna (la scena osservata e reificata da un osservatore-interprete) struttura la Recherche così come L'Être et le Néant. L'A. analizza inoltre alcuni passi de Les mots come un «Combray» capovolto: per Sartre come per Proust, l'infanzia borghese è fondata sull'ambiguità. Certo è che, rispetto a Proust, Sartre ribalta il rapporto che esiste tra letteratura e vita.

4 L'opera di Proust subisce una personalissima declinazione in Deleuze. Il capitolo a lui dedicato, «Hors sujet» (pp. 117-154), indaga proprio le ragioni del Proust rizomatico e orizzontale letto da Gilles Deleuze. Nonostante il fascino per Proust et les signes, l'A. insiste soprattutto su quanto della visione del sensibile e dell'ambiguità proustiana venga distorto dalla griglia deleuziana: l'unità sistematica cui mira il filosofo analizzando Proust è una chimera. Le successive edizioni del saggio mostrano altresì come la macchina deleuziana si pieghi progressivamente seguendo strutturazioni del pensiero più attente alla molteplicità (la «nébuleuse»). Un altro modo attraverso il quale il filosofo si appropria di Proust è basato sull'idea di lettura, intesa come fonte di malintesi e di tradimento delle intenzioni autoriali. Infine, se solo un certo tipo di bestiario proustiano è privilegiato da Deleuze, è perché così ci restituisce un Proust analizzato intuitivamente, a volte impropriamente, e dunque estremamente personale.

5 Con il «Moi idéal (Barthes)» (pp. 155-194) il saggio si avvia alla conclusione: siamo di fronte a una trasformazione di Proust nel fantasma dell'io ideale (le «marcellisme»). Barthes rimodella la biografia di Proust per le proprie esigenze teoriche, insistendo in particolare sulla dialettica tra frammento e continuità creativa. Negli appunti de La préparation du roman, Proust si deforma fino a diventare modello del grande scrittore vagheggiato dallo stesso Barthes; lo stile di alcune sue affermazioni mostra fino a che punto Proust sia stato assimilato dal filosofo; ne La chambre claire, infine, la gemellarità dei due si basa in particolare sul processo di «surimpression».

Nella conclusione (pp. 195-208) che precede la ricca bibliografia, l'A. ribadisce la necessità di ridefinire la filosofia dei quattro autori a partire dai concetti di «pensées sensibles» e di «milieu», di cui Proust diventa modello plastico e nutrimento intellettuale. 